\title{
On the relation between the internal friction and resistance of solutions of salts in various solvents
}

\section{Eilhard Wiedemann}

To cite this article: Eilhard Wiedemann (1883) On the relation between the internal friction and resistance of solutions of salts in various solvents, Philosophical Magazine Series 5, 16:102, 459-460, DOI: 10.1080/14786448308627465

To link to this article: http://dx.doi.org/10.1080/14786448308627465

曲 Published online: 28 Apr 2009.

Submit your article to this journal $₫$

Џ Article views: 2

Q View related articles ๘ 
the inductive force is

$$
\mathrm{Y}_{1}=\frac{\mathrm{K}}{2} m \frac{d i}{d t} \pi \sin \epsilon \frac{\rho^{2}}{\mathbf{R}^{2}} \frac{\pi \rho}{2 l} \frac{\rho}{3 \lambda}\left(1-\frac{\rho^{\prime 2}}{\rho^{2}}\right)
$$

Here $\rho, \rho^{\prime}$ are the exterior and interior radii of the system ; $\lambda$ is the constant distance which separates two consecutive surfaces.Comptes Rendus de l'Académie des Sciences, Oct. 8, 1883, pp. 800802 .

ON THE RELATION BETWEEN THE INTERNAL FRICTION AND RESISTANCE OF SOLUTIONS OF SALTS IN VARIOUS SOLVENTS. BY EILHARD WIEDEMANN.

In connexion with a remark of $G$. Wiedmann* attempts have in recent times been frequently made to establish strict numerical relations between the coefficients of friction and the conductivity for voltaic electricity, against the universality of which, however, he raises theoretical objections. Experimenters on this subject have either followed the change in the above magnitudes with the temperature in the same solution, or with the concentration in various solutions; and a certain analogy has been ascertained to exist between the two processes. For a strict investigation, solutions of the same salt should be investigated which have as different coefficients of friction as possible. I have therefore made some experiments with solution of zinc sulphate in water and in aqueous glycerine. A special investigation showed that the glycerine was quite free from acid, and conducted the current very badly.

The resistances to friction were determined with the apparatus described by Sprung $\uparrow$; the electrical resistances were determined by Wheatstone's bridge. Solutions of zinc sulphate in water and in glycerine of the same strengths were placed in two troughs of equal dimensions, and two equal amalgamated zinc plates were dipped in them. Both troughs were simultaneously introduced into the two arms of the bridge.

In the first series of experiments the solutions were prepared by dissolving 10 parts of $\mathrm{ZnSO}_{4}+7 \mathrm{H}_{2} \mathrm{O}$ in 100 parts of water, and then making this solution up to $500 \mathrm{c}$. c. by the addition of $50 \mathrm{c}$. c., 100 c. c., or 250 c. c. of water or of glycerine. Hence the solutions always contained an equal number of molecules of the salt in equal volumes.

For the solutions in water and glycerine the following ratios were obtained:-

$$
\begin{aligned}
& \text { Internal } \\
& \text { Friction. Resistance. } \\
& 50 \mathrm{Zn} \mathrm{SO}_{4} \ldots .1: 68 \cdot 7 \quad 1: 12 \cdot 1 \\
& 100 \mathrm{Zn} \mathrm{SO}{ }_{4} \ldots .1: 29.8 \quad 1: 9.52 \\
& 250 \mathrm{Zn} \mathrm{SO} \mathrm{SO}_{4} \ldots 1: 6.15 \quad 1: 3.68
\end{aligned}
$$

* G. Wiedmann, Galvan. 2 ed. i. p. 631 et seqq. ; 3 ed. i. p. 952.

+ Pogg. Ann. clix. p. 1, 1876. 
In all cases the solution of glycerine showed the greater frictional and electrical resistances.

The second experiment was made by dissolving $50 \mathrm{gr} . \mathrm{ZnSO}_{4}$ $+7 \mathrm{H}_{2} \mathrm{O}$ in water to a volume of $500 \mathrm{c.c.}$; and on the other hand $50 \mathrm{gr}$. of $\mathrm{ZnSO}_{4}$ was dissolved in a little water, and made up to 500 c. c. by glycerine.

It was not possible to dissolve zinc vitriol directly in glycerine, because glycerine first of all withdraws water from this salt, and the salt with a smaller quantity of water of crystallization dissolves with difficulty in glycerine.

In this case the ratios were:-

Frictional resistance $1: 86 \cdot 2$; Electrical resistance $1: 109$.

The above numbers show throughout that no proportionality exists between frictional and electrical resistance; but that the solvent has a predominant influence in the processes in question. It follows moreover that the more concentrated are the solutions the less predominant is the influence of the solvent.

Leipzig, August 1883.

\section{SPECTROSCOPIC NOTES. \\ BY PROFESSOR C. A. YOUNG, PRINCETON, N. J.}

For the past few months I have been examining the spectra of sun-spots with great care, and with an instrument of high dispersion. The spectroscope employed consists of a comet-seeker of five inches aperture and about forty-eight inches focal length, used both as collimator and view-telescope after Littrow's method, the slit and diagonal eye-piece being as close together as it is convenient to place them. A small spot of black paper, about three tenths of an inch in diameter, is cemented to the centre of the object-glass (as suggested by my colleague, Professor Brackett, in a note published in the American Journal of Science, July 1882), and entirely destroys the internal refiections, which would otherwise most seriously interfere with vision.

The dispersion is obtained by one of Professor Rowland's magnificent gratings on a speculum-metal plane, with a ruled surface three and one-half inches by five, 14,000 lines to the inch. The slit and eye-piece of the telescope are so placed that the line joining them is parallel to the lines of the ruling. An instrument of this sort is incomparably more convenient than one in which the collimator and view-telescope are separate, though of course, on account of the inclination of the visual rays to the axis of the object-glass, there is a little aberration, and the maximissimum of definition is not quite reached. There is no difficulty, however, in seeing easily the duplicity of the $b$ 's, $\mathrm{F}_{\mathrm{v}}$, and other similar tests with the instrument thus arranged. The spectroscope is mounted upon a strong plank, stiffly braced, and this is attached by powerful 